\title{
Sınıf Yönetimine Ait Temel Ögelerin Yaratıcı Drama Yöntemiyle İşlenmesi
}

\author{
Şeyda Orhan ${ }^{1}$
}

Özlem Öznur Gökbulut²

\begin{abstract}
$\ddot{O z}$ et
Sınıf yönetimine ait temel ögelerin yaratıcı drama yöntemiyle işlenmesi adlı bu çalışmada amaç, farklı bölümlerde ögrenim gören aday öğretmenlerin sınıf yönetimi konusunda çalışma kapsamında olan ögelere yönelik çeşitli bilgilere sahip olmalarını săglamaktır. Projenin konusu olan sınıf yönetimi burada alt başlıklarından; sınıf yönetiminde bazı temel kavramlar, sınıf yönetimini etkileyen faktörler, sinıf yönetimi açısından öğretmende bulunması gereken özellikler, sınıfta istenmeyen davranışlar olarak sinırlandırllmıştır. Bu projede nitel ve nicel çalışma modelleri birlikte kullanılmıştır. Ön test ve son test olarak Delson (1982) tarafından geliştirilmiş, geçerlik ve güvenirliği Yalçınkaya ve Tonbul (2002) tarafından yapılan 'Sınıf Yönetimi Becerileri Gözlem Ölçeği' uygulanmıştır. Çalışmanın nitel verileri ise öğretmen adaylarına uygulama öncesi ve sonrasında yöneltilen açık uçlu sorular ile toplanmıştır. Proje yaratıcı drama yöntemiyle sınıf yönetimine ait belirlenen ögelerin işlenmesi amacıyla, 27 kişiden oluşan gönüllü EYAT (Ankara Üniversitesi Eğitimde Yaratıcı Drama Topluluğu) ögrencileri ile üçer saatlik altı oturum olarak toplam 18 saatlik atölye çalışması ile uygulanmıştır.

Yaratıcı drama uygulamaları, ögretmen adaylarının sınıf yönetimi ve sınıfta istenmeyen davranışları karşılama becerilerine olumlu yönde etkilemiştir. Öğretmen adaylarının ĕgitilmesinde sınıf yönetimi gibi uygulamaya dayalı derslerde yaratıcı drama gibi yine uygulamaya dayalı yöntemlerin işe koşulması önerilmektedir. Yaratıcı drama gibi farkl yöntemlerin öğretmen eğitimlerinde işe koşulmaslyla öğretmen ve öğretmen adaylarl; meslekteki çalışma koşulları, süreleri ve mesleğe karşı duygu ve tutumlarına paralel olarak kendilerini yenilemek ve eğitim dünyasındaki yeni gelişmeleri sınıf ortamına taşımak için motive edilmelidir.
\end{abstract}

Anahtar Sözcükler: Ĕ̈itim, sınıf, yönetim, sinıf yönetimi, aday öğretmen, yaratıcı drama.

\section{The Use of Basic Methods on Classroom Management Through Creative Drama}

\begin{abstract}
The purpose of the paper is to present some valuable information to prospective teachers of various fields regarding classroom management The main title of the project, classroom management, is classified in subtitles as follows; some basic elements of classroom management, factors influencing classroom management, qualifications about classroom management that teachers should possess, undesired behaviors in class. Quantitative and qualitative methods are both used in the project. 'Classroom Management Skills Observation Scale' by Delson (1982) was used as preliminary and conclusion test, which is verified by Yalcinkaya and Tonbul (2002) Quantitative datum of the workshop were collected through open ended questions directed to prospective teachers before and after the application of the project. Methods and techniques used in the workshop are creative drama technique and inanimate image regarding the method, role corridor, method
\end{abstract}

1 Öğretmen, Milli Eğitim Bakanlığı, seydaooorhan@gmail.com

2 Bil.Uzm. Öğretmen, Milli Eğitim Bakanlığı, ooozlemgokbulut@gmail.com 
of teaching via techniques on involvement of the leader, answer-question and concept map. The project was carried out through the use of creative drama technique aiming to employ the elements of classroom management by 27 volunteer students of EYAT (Ankara University Creative Drama Education Society) during six sessions of three hours totaling 18 hours.

As a result, creative drama methods influenced prospective teachers in a positive way helping them coping with classroom management and undesired behaviors. Thus, the use of creative drama which is also an applied course as classroom management in educating prospective teachers.

Key Words: Education, classroom, classroom management, prospective teacher, creative drama.

\section{Giriş}

Sınıf yönetimi, sınıf içi etkinlikleri öğrenme odaklı olarak etkili bir biçimde düzenleyip sürdürme ve öğrenci davranışlarına rehberlik etme sürecidir (Şişman, 2007, s.87). Eğitim amaçlarına ulaşma hedefiyle, sınıf içinde var olan sınıfın etkileşim halinde olduğu tüm faktörlerin düzenlenmesidir. Etkili ve verimli bir sınıf yönetimi öğrencinin, bireysel, sosyal, kültürel ve demokratik yönden gelişimine önemli katkılar sağlar. Bu katkılar öğrencinin gelecekteki yaşantısına da yansır (Güneş, 2007, s.27).

Sınıflar, eğitim - öğretim etkinliğinin yeridir. Öğrenciler de günlük yaşamlarının büyük bir bölümünü sınıflarda geçirmektedirler. Bu nedenle, sınıf yönetimini oluşturan, etkileyen tüm etmenler en iyi şekilde yapılandırılmalıdır. Her sınıfın kendine özgü bir yapısı vardır. Bu yapıyı oluşturan tüm özellikler sınıf yöneticisi tarafından yönetilmelidir.

Olumlu bir sınıf ikliminin oluşturulmasında rol oynayan en önemli öge, kuşkusuz öğretmenin insani ve mesleki yönden sahip olduğu özelliklerdir (Turan, 2007, s.3). Yönetici olarak öğretmen, sahip olduğu özelliklerin yanı sıra, sınıf yönetimini etkileyen faktörleri iyi tanımalı ve olumlu bir sınıf ortamı için bunları ustaca kurgulayabilmelidir.

Sınıf yönetimini etkileyen birçok sınıf içi ve dışı faktör söz konusu olabilir. Ülke yönetim biçimi, okul yönetimi, toplumsal yapı, aile gibi başlıklar sınıf dışı faktörler; sınıfın fiziksel yeterliği, sınıfta gerekli araçgereçlerin varlı̆̆ı, öğretmenin alan yeterliği, öğrenme-öğretme sürecindeki yeterliği, sınıf üyelerinin iletişim durumları, sınıftaki öğrenci yapısı gibi başlıklar sınıf içi faktörler olarak ele alınabilir. Öğretmen, sınıf yönetim başarısı ve motivasyonu açısından bu özelliklerden etkilenmektedir.

Aday öğretmenler, sınıf yönetimine dair hümanist bir tutum sergilerken, mesleğe başladıktan sonra daha sert, otoriter bir sınıf yönetimi anlayışına sahip olmaktadır. Bu da verilen sınıf yönetimi eğitiminin gerçeklerden uzak olduğunun göstergesi olabilir (Celep, 2007). Günümüzde öğretmen yetiştiren kurumların eğitim programlarında aday öğretmenler için yer alan sınıf yönetimiyle ilgili teori derslerinin, uygulama ve gözlem ile yeterli ölçüde desteklenmesi gerekmektedir. Hatta öğretmen adaylarının mesleki gelişimleri için onların da merkezinde olduğu, yaşantı yoluyla öğrendiği, kalıcı bilgi ve beceriyi edindikleri öğrenme süreçleri oluşturulmalıdır. Bu süreçler özellikle sınıf ortamına ağırlıklı olarak öğretmenin davranış ve tutumuyla yansıyan mesleki becerilerin geliştirildiği sınıf yönetimi gibi dersler için işlevsel olabilir.

Sınıf yönetiminde öğretmenlerin motivasyonlarını etkileyen birçok etmen vardır. Öğretmen adaylarının, sınıf yönetimiyle ilgili kazandırılmak istenen bilgi ve becerileri içselleştirmeleri, onların mesleki becerilerinin yeterliği açısından oldukça önemlidir.

Öğretmen adaylarının mesleğe başlamadan önce sınıf yönetimine dair kalıcı bilgi edinmelerinin sınıf içi uygulamalarını olumlu etkileyeceği düşünülmüştür. Farklı bölümlerde eğitim gören öğretmen adaylarıyla 
gerçekleştirilen bu çalışmada ise yaratıcı drama araç/ yöntem boyutuyla ele alınmıştır. Öğrenenin merkezde olduğu bir aktif öğrenme yöntemi olan yaratıcı drama ile "sınıf yönetimine ait temel kavramlar", "sınıf yönetimini etkileyen iç ve dış faktörler", "sınıf yönetiminde öğretmenin önemi ve görevi” olmak üzere sınıf yönetimiyle ilgili bazı alt başlıklara dair kalıcı öğrenmenin sağlanması amaçlanmıştır.

En genel yanıyla eğitimde yaratıcı drama; herhangi bir konuyu, doğaçlama, rol oynama gibi tekniklerden yararlanarak, bir grupla ve grup üyelerinin birikimlerinden, yaşantılarından yola çıkarak canlandırmalar yapmaktır. Bu canlandırma süreçlerinde oyunun genel özelliklerinden yararlanılır ve bir lider, drama öğretmeni/ eğitmeni eşliğinde ve yapılacak çalışmanın amacına, grubun yapısına göre önceden belirlenmiş mekânda yaratıcı drama süreci gerçekleştirilir (Adıgüzel, 2006). Bu çalışma, yaratıcı drama yöntemiyle kalıcı bilgi edinmenin beraberinde, yaratıcı drama yöntemiyle "sınıfta istenmeyen davranışların nasıl yönetileceğine dair bir farkındalık sürecini de kapsamaktadir.

Sınıf yönetiminde öğretmenler, sınıfın fiziksel koşullarındaki yetersizlik, sınıf kurallarını belirlemedeki zorluklar, öğretim etkinliklerindeki aksaklıklar gibi bazı olumsuzluklarla karşılaşabilirler. Bu olumsuzluklardan biri de "istenmeyen davranışlar" dır. Yani öğrencilerin sınıfta, bireysel veya grup halinde gerçekleştirdikleri, eğitim hedeflerine ulaşmayı engelleyen her türlü uygunsuz davranış biçimidir.

Sınıfta istenmeyen davranışların nasıl yönetileceği konusunda öğretmen adaylarının becerilerini geliştirme firsatı bulacakları öğrenme ortamlarına ihtiyaçları vardır. Öğretmen, sınıf ortamında istenmeyen bu davranışın nedenini bulmak zorundadır. Öğretmenin istenmeyen bu davranışın nedenini bulması ve bu nedene göre harekete geçebilmesi için öğretmen, öğrencileri anlamaya çalışmalı hatta onlarla empati kurabilmelidir. Öğretmenlerin yanlış tutumları, öğrencilerin istenmeyen davranışlar ortaya koymasına neden olabilir.

Yaratıcı dramada empatik iletişim kurulmaya çalışılır. Bunun anlamı, gerçek yaşamdaki gibi bir yandan bireyler arası iletişimi kolaylaştırmak, diğer yandan da bireylerin çevreleriyle olan etkileşimlerini güçlendirmektir. Bir çalışmada hiç tanınmayan bir kişinin kimliğine bürünüp onun ne söylediğini dinleyip, onu anlamaya çalışmak ve onun duygularını hissetmek empatik iletişim geliştirme adına yapılabilecek önemli bir çalışmadır ( Üstündağ, 2003, s.48).

Sınıf, öğrenmenin gerçekleştiği değişken ve oldukça dinamik bir ortamdır. Bu ortamı dinamik kılan etmenler arasında fiziksel olarak ortamdaki öğrenme araçlarının ve mekanın organizasyonu, öğrencilerin sınıf ortamına taşıdığı davranış biçimleri, öğrenme stilleri gibi çeşitli örnekler yer alabilir. Sınıfta öğrenmenin en üst düzeyde olabilmesi için öğretmenin tüm bu etmenleri en iyi şekilde organize etmesi gerekmektedir. Bu durum, öğretmen için bir çeşit kurgu yapma işlemi olarak görülebilir. Öğretmen iyi bir gözlemci olarak süreçte yer alırken olası olumsuzluklar da başa çıkabilecek kadar yeterli problem çözme becerisine sahip olmalıdır. Söz konusu olan bu becerilerin büyük oranda yaşantılar ve deneyimler yoluyla geliştiği düşünülmektedir.

Katılımcı, yaratıcı drama süreçlerinde bir durumun, çatışmanın içine girer, kurgusal gerçeklikte bu çatışmayı yaşar, grupla ve grup içi iletişimle irdelemeye başlar, dener, sorgular, yeniden analiz eder ve gerçeklik arasında özellikle drama tekniklerinin de yol göstermesiyle sürecin tam kendisi olur, onu yaşar ve bu sürecin devamını belirler (Adıgüzel, 2006).

Çalışma kapsamında öğretmen adaylarıyla sınıf yönetiminin ögelerine dair kalıcı öğrenmenin sağlanması amacıyla ve kurgusal gerçeklik çerçevesinde sınıf ortamındaki problem durumları yine öğretmen adaylarının farklı sınıf yönetimi yaklaşımlarını role girerek deneyimlemelerinin aday öğretmenlerin sınıf yönetimi becerilerini geliştireceği düşünülmektedir.

Sonuç olarak bu çalışmada meslek yaşamları başlamadan önce aday öğretmenlere öğrenci davranışlarını yönetebilmek, sınıfta tercih edecekleri öğretmen tutumları hakkında fikir verebilmek ve sınıf yönetimine dair 
kavramları hangi durumda nasıl işe koşacaklarını deneyebilmek adına canlandırmalar yoluyla gerçekçi bir kurgusal bir yaşantı ortamı sunularak sınıf yönetimine yönelik becerilerinin geliştirilmesi amaçlanmıştır.

\section{Yöntem}

Bu bölümde araştırmanın modeli, çalışma grubu, veri toplama araçları, verilerin toplanması ve uygulama surecine yer verilmiştir.

\section{Araştırma Modeli}

Çalışma kapsamında durum çalışması kullanılmıştır. Konu hakkında ön keşif çalışması olarak düşünülebilecek olan durum çalışması; bir kişinin, bir durumun, bir olgunun ya da olayın belli bir odak çerçevesinde ayrıntılı incelenmesidir (Yıldırım ve Şimşek, 2003). Bu araştırmada da belirli bir grup üzerinde bazı kavramlar odağa alınarak nitel incelemeler yapıldığı için, çalışmaya durum çalışması denebilir.

\section{Çalışma Grubu}

Bu çalışma, farklı bölümlerde eğitim gören ve EYAT (A. Ü. Eğitim Bilimleri Fakültesi Yaratıcı Drama Topluluğu) üyesi olan 16 kadın, 11 erkek olmak üzere toplam 27 aday öğretmenin katılımıyla gerçekleştirilmiştir. Çalışma grubunda gönüllü olarak yer alan öğrencilerden 17'si sınıf öğretmenliği, 4'ü okulöncesi öğretmenliği, 2'si din kültürü öğretmenliği, 1'i sosyal bilgiler öğretmenliği, 1'i zihin engelliler öğretmenliği, 1'i bilgisayar ve öğretim teknolojileri öğretmenliği, 1'i rehberlik ve psikolojik danışmanlık bölümüne devam etmektedir. Aday öğretmenler, temel düzeyde yaratıcı drama yaşantısına sahiptir.

\section{Veri Toplama Araçları}

Çalışmada nitel ve nicel veri toplama araçları kullanılarak karma yönteme başvurulmuştur. Ön test ve son test olarak Delson (1982) tarafından aday öğretmenler için geliştirilmiş, Türkçe’ye uyarlanışı ise Yalçınkaya ve Tonbul (2002) tarafindan yapılan 'Sınıf Yönetimi Becerileri Gözlem Ölçeği’ uygulanmıştır. Bu ölçek uygulanmadan önce, madde ifadeleri üç alan uzmanı tarafından, bu araştırmada bulunan aday öğretmenlere göre düzenlenmiştir. Çalışma grubu uygulama sürecinden önce ve uygulama sonrasında kendilerine yöneltilen ölçeği ve açık uçlu soruları tüm grup bir arada iken yaklaşık bir saatte yanıtlamışlardır.

Bunun yanı sıra nitel veriler için öğretmen adaylarına uygulama öncesi ve sonrasında açık uçlu sorular yöneltilmiş, yanıtlar betimsel analiz yoluyla sınıflandırılmıştır. Sorular, üç alan uzmanı tarafindan kontrol edilmiş ve araştırmacılar tarafından ortak görüş sağlandıktan sonra görüşme formu son halini almıştır. Oturum sürecindeki nitel veriler ise çalışmayı gerçekleştiren araştırmacının katılımcılardan aldığı yazılı kayıtlarından hareketle elde edilmiştir.

\section{Uygulama Süreci}

2009-2010 öğretim döneminde üçer saatlik altı oturum olarak toplam 18 saatten oluşan uygulama sürecinin ilk oturumu 'uyum çalışması', ikinci oturumu eğitim ve sınıf yönetimine dair 'kavramsal atölye', üçüncü oturumu 'sınıf yönetimini etkileyen faktörler', dördüncü oturumu ‘öğretmen karakterlerini oluşturma', beşinci oturumu 'sınıf yönetimi ve öğretmen özellikleri', altıncı oturumu ise 'sınıfta istenmeyen davranışlar' başlıklarına yönelik gerçekleştirilmiştir.

Çalışmanın yaratıcı drama atölyelerinde kurgu; Adıgüzel (2006)'in "Hazırlık - 1sınma, canlandırma ve değerlendirme" den oluşan aşamalandırma sistemine göre yapılandırılmıştır. 
İlk atölyede grup üyelerinin çalışma için gerekli olan grup dinamiğine ulaşabilmeleri amacıyla gerçekleştirilen uyum çalışmalarından sonra, ikinci oturumda eğitim ve sınıf yönetimine dair genel kavramlar, üçüncü oturumda ise sınıf yönetimini etkileyen faktörler yaratıcı drama yöntemiyle işlenmiştir. Böylelikle sınıf yönetimine daha eleştirel bakabilmek için gerekli olduğu düşünülen temel kavramlara yönelik hazır bulunuşluk düzeyi kontrol edilmiştir. Özellikle öğretmenlik eğitiminin ilk yılında olan veya sınıf yönetimi dersini henüz almamış olan öğretmen adaylarına sınıf yönetimine dair çeşitli bilgiler kazandırılmak istenmiştir. Dördüncü oturumda ise öğretmen adaylarına verilen nesnelerden yola çıkılmış ve dört farklı yapıya sahip öğretmen karakterleri oluşturulmuştur. İsimlerinin de gruplar tarafından belirlendiği ve sınıfta farklı tutumlar sergileyen bu öğretmen karakterlerinin sınıflarında oluşturduğu atmosfer yaratıcı drama teknikleriyle bu atölye sürecinde kurgulamıştır. Beşinci atölyede ise, öğretmen adayları dört farklı sınıf ortamı kurgusu içinde, oluşturulan öğretmenlerin özelliklerini ve sınıf yönetimiyle bu öğretmen özelliklerinin bağlantılarını incelemiştir. Buradan hareketle kurgulanan bu sınıf ortamı ve öğretmenlerin sınıf yönetimi kuralları ile ortaya çıkabilecek istenmeyen davranışlar ve bu davranışlara dönük çözüm noktaları drama teknikleriyle ortaya konmaya çalışılmıştır. Oturumların değerlendirme ve ara değerlendirme aşamalarında aday öğretmenlerin kurgusal olan sınıf ortamları ile kendi oluşturacakları gerçek sınıf ortamları arasında bağ kurmaları sağlanmaya çalışılmıştır.

\section{Bulgular ve Yorum}

Araştırmaya katılan öğretmen adaylarının uygulama öncesi ve sonrası "Sınıf Yönetimi Becerileri Gözlem Ölçeği”nden aldıkları toplam puanlar bağımlı gruplar t-testi ile karşılaştırılmıştır. Araştırmaya katılan öğretmen adaylarının uygulama öncesi ve sonrası "Sınıf Yönetimi Becerileri Gözlem Ölçeği”"nden aldıkları puanlar bağımlı gruplar t-testi ile karşılaştırılmıştır. Sonuçlar Tablo 1'de sunulmuştur.

Tablo 1. Öğretmen Adaylarının Ölçekten Aldıkları Ön test ve Son test Ortalama Puanlarının t-Testi Sonuçları

\begin{tabular}{ccccccc}
\hline $\begin{array}{c}\text { Sinıf Yönetimi } \\
\text { Becerileri }\end{array}$ & $\mathrm{N}$ & $\mathrm{X}$ & $\mathrm{Sd}$ & $\begin{array}{c}\text { Serbestlik } \\
\text { derecesi } \\
\text { (sd) }\end{array}$ & $\mathrm{t}$ & $\mathrm{p}$ \\
Gözlem Ölçeği & 27 & 80,2 & 11,26 & & & \\
\hline Öntest & 27 & 85,3 & 9,77 & & & \\
Sontest & $27,0,67$ & & $0,001^{*}$ \\
\hline
\end{tabular}

$* \mathrm{p}<0,05$

Grupların ön test ve son testten aldıkları puanların aritmetik ortalamaları incelendiğinde, öğretmen adaylarının ön uygulamadaki toplam puan ortalamaları 80,2 iken son uygulamada bu puan ortalamasının 5,1 puan artarak 85,3 olduğu görülmüştür. Ayrıca grupların standart sapma puanlarına bakıldığında, grubun son uygulamada ölçeğe yönelik daha homojen yanıtlar verdiği görülmüştür. Bu durum sonucunda yapılan uygulamanın, grubu ölçekte ölçülen özelliklere karşı ortak görüşte buluşturduğu söylenebilir. İki grubun ön ve son ölçek uygulama puanları arasında istatistiksel olarak anlamlı bir fark bulunmuştur (t $(27)=-3,67 ; \mathrm{p}<0.05)$. 
Araştırmanın temel yöntemi olan yaratıcı dramanın aday öğretmenlerin sınıf yönetim becerilerini artırma konusunda etkili olduğunu iddia edebilmek için çalışmaya aynı özelliklere sahip bir kontrol grubunun da dahil edilmesi gerekir. Ancak bu çalışma tek grup üzerinden yürütülen bir çalışma olduğu için, istatistiksel sonucu betimsel sonuçlarla birleştirdiğimizde çalışma grubunun sınıf yönetimi becerilerinde gelişme kaydettiği belirtilebilir.

Yukarıdaki ölçeğe ek olarak öğretmen adaylarına kendilerini sınıf yönetimi becerisi açısından ne kadar yeterli hissettikleri sorulmuştur. Katılımcıların uygulamadan önce ortalama 6,48 puan ile kendilerini orta düzeyde hissettikleri, ama uygulamadan sonra bu puanın 7,30’a çıktığı, dolayısıyla bir artış gözlemlendiği söylenebilir.

\section{Öğretmen Adaylarının Sınıf Yönetimi Hakkındaki Görüşlerine İlişkin Bulgular}

Öğretmen adaylarına sınıf yönetimine ilişkin sorulan açık uçlu sorulara verdiği yanıtlar soru bazında incelenmiştir. Öncelikle bu yanıtlar araştırmacıların önceden belirlediği kodlara göre üç farklı kişi tarafından okunmuş, katılımcılardan gelen yanıtlara göre kodlar düzenlenmiş ve aşağıda sunulan temalar bağlamında yanıtlar analiz edilmiştir.

\section{1. "Sınıf yönetimi nedir?" sorusuna verilen yanıtların analizi}

$\mathrm{Bu}$ soruya ön uygulamada verilen yanıtlar incelendiğinde, katılımcıların yanıtlarının dört tema altında toplanabileceği görülmüştür. Bunlar; etkili ve verimli öğrenme, sınıfın fiziksel düzenlenmesi, sınıf atmosferi ve sınıftaki ilişkilerdir. Öğretmen adaylarının son uygulamada verdikleri yanıtlar incelendiğinde ise yukarıdaki temalara ek olarak sınıf yönetimini etkileyen faktörler, akademik başarının yükselmesi temaları da bulunmuştur. Bu yeni temalara yönelik öğretmen adaylarının ön uygulamada yazdıklarından örnekler şu şekilde gösterilebilir:

\section{Etkili ve verimli öğrenme}

"Etkili ve verimli öğretimin gerçekleşmesi için sınıfın gerek fiziksel düzenlemesini gerek öğretimin planlanması kapsayan ve öğrenme ortamında dersin işlenişini olumsuz etkileyen istenmedik davranışlara yer vermemektir" (ÖA1)

\section{Sınıfın fiziksel düzenlenmesi}

"Sınıfın temizliğini, düzenini, dersin sınıfa uygun olarak işlenişi hangi yöntemi uygulamayı, sınıf içinde uygulanacak bütünlük sağlayan davranışların tümü ” (ÖA2)

\section{Sinıf atmosferi}

“Öğrencilerin fiziksel psikomotor, duyuşsal gelişimlerini sağlamak için sınıfta etkili bir ortam oluşturmak" (ÖA3)

\section{Sınıftaki ilişkiler}

“Öğretmen öğrenci ilişkilerinin iyi olmasını sağlamaktır” (ÖA4)

Ön uygulamadaki temalara ek olarak öğretmen adaylarının son uygulamada yazdıklarından örnekler ise şöyledir.

\section{Sınıf ortamını etkileyen faktörler}

"Öğretmen ve öğrencinin etkileşime geçtiği sınıf ortamının, sınıfı etkileyen iç ve dış etmenleri göz önüne alarak yönetilmesidir” (ÖA5) 


\section{Akademik başarının yükselmesi}

"Eğitim öğretimde sınıfın başarı oranının yükseltilmesidir" (ÖA6)

\section{2. "İyi bir sınıf yönetimi becerisine sahip öğretmenin özellikleri neler olabilir? Listeleyiniz" sorusuna verilen yanıtların analizi}

$\mathrm{Bu}$ soruya verilen yanıtlar, proje kapsamında katılımcılar tarafindan oluşturulan öğretmen karakterlerine paralel olarak belirlenen öğretmen özellikleri olan "alan hakimiyeti, bireysel özelliklere önem verme, iletişim becerisi gelişmiş, olumlu bir sınıf ortamı yaratma" olmak üzere dört tema açısından incelenmiştir. Ön uygulamada bu temalara değinen öğretmen adaylarının sayısı oldukça az iken, son uygulamada aday öğretmenlerin büyük oranda bu temaların iyi bir sınıf yönetimi becerisine sahip olan öğretmen özelliği olarak listeledikleri görülmüştür.

Altı oturumluk yaratıcı drama uygulamasından sonra öğretmen adaylarında iyi bir sınıf yönetimi becerisine sahip öğretmen özelliklerinden belirlenen dört tanesini öğrendikleri düşünülmektedir. Özellikle öğretmenin bir yönetici olarak sınıftaki yanlış uygulama ve tutumu sınıfta öğrencileri istenmeyen davranışlar oluşturmaya yönlendirebilir veya bu davranışların şiddetini güçlendirebilir. Bu yüzden öğretmenin benimsediği kendi yönetim kuralları oldukça önemlidir. Olumlu bir sınıf ortamı yaratmak için öğretmenin özelliklerinin ve öğretmenin sınıf yönetimi kavramının neresinde olduğunun yanıtı projede yer alan öğretmen adayları tarafından keşfedildiği söylenebilir.

\section{3. “İyi bir sınıf yönetimi becerisiyle yönetilen bir sınıfın özellikleri neler olabilir?” sorusuna verilen yanitların analizi}

$\mathrm{Bu}$ soruya ön uygulamada verilen yanıtlar incelendiğinde katılımcıların yanıtlarının iki tema altında toplanabileceği görülmüştür. Bunlar; demokratik değerler ve derse aktif katılımdır.

Öğretmen adaylarının son uygulamada verdikleri cevaplar incelendiğinde ise yukarıdaki temalara ek olarak akademik başarısı yüksektir, sınıf üyelerinin iletişim gücü yüksektir, sınıfüyeleri görevlerini tanımlayabilir ve sınıf ortamı öğrenci ihtiyaçlarını karşılar temaları da bulunmuştur.

Öğretmen adaylarının ön test ve son testte "iyi bir sınıf yönetimi becerisiyle yönetilen sınıf özellikleri neler olabilir? Listeleyiniz" sorusuna verdikleri cevaplar incelendiğinde; ön teste göre belirtilen özelliklerin çeşitliliği artmıştır.

\section{Sınıf yönetimi becerisi konusunda eksik olduğunuzu düşündüğünüz kısımlar nelerdir? Açıklayınız" sorusuna verilen yanıtların analizi}

$\mathrm{Bu}$ soruya ön testte verilen yanıtlar incelendiğinde katılımcıların yanıtlarının iki tema altında toplanabileceği görülmüştür. Bunlar; "uygulama eksikliği”" ve "uygulama yapmadığım için bilmiyorum” ifadeleridir. Öğretmen adaylarının son testte verdikleri cevaplar incelendiğinde ise yukarıdaki temalardan uygulama eksikliğine ek olarak, problem durumların çözümü için “deneyimsizim” teması eklenmiştir. Uygulama yapmadığım için bilmiyorum ifadesi hiç kullanılmamıştır.

\section{5. Öğretmen adaylarının ön uygulama ve son uygulama "sınıf yönetimi becerisi konusunda eksik olduğunuzu düşündüğünüz kısımlar nelerdir? Açıklayınız” sorusuna verilen yanıtların analizi \\ Katılımcıların bu soruya verdikleri yanıtlar incelendiğinde; ön uygulamada verilen uygulama yapmadığım için "bilmiyorum" yanıtının son uygulamada yer almamış olması projedeki yaratıcı drama uygulamalarının aday öğretmenlere sınıf yönetiminde öğretmenin yeri ve kendi sınıf yönetimi becerileri ile ilgili fikir verdiği söylenebilir. Ayrıca sınıfta bir yönetici konumundaki becerilerini değerlendirme olanağı verdiğini gösterebilir.}


Öğretmenin bir yönetici olarak sınıftaki yanlış uygulama ve tutumu, sınıfta öğrencileri istenmeyen davranışlar oluşturmaya yönlendirebilir veya bu davranışların şiddetini güçlendirebilir. Bu yüzden öğretmenin benimsediği kendi yönetim kuralları oldukça önemlidir. Bu açıdan öğretmen adaylarının iyi bir sınıf yönetimi becerisine sahip öğretmenin özelliklerine yönelik oluşturdukları liste incelendiğinde olumlu bir sınıf ortamı yaratmak için öğretmenin özelliklerinin ve öğretmenin sınıf yönetimi kavramının neresinde olduğu yanıtının çalışmada yer alan öğretmen adayları tarafından keşfedildiği söylenebilir.

\section{Sonuç ve Öneriler}

Bu çalışmada, yaratıcı drama uygulamalarının öğretmen adaylarının sınıf yönetimi becerilerine ve sınıf yönetiminde öğretmene ait sorumluluklara yönelik ve sınıfta istenmeyen davranışları karşılama konusundaki becerilerine yönelik farkındalıklarını olumlu yönde etkilediği belirlenmiştir. Öğretmen adaylarının kendi mesleki gelişim süreçlerinde yaratıcı drama gibi farklı yöntemlerin kullanması, onların da sınıf içi uygulamalarında yaratıcı drama gibi yöntemleri kullanmaları yönündeki motivasyonlarını artıracağı düşünülmektedir. Özellikle sınıf yönetimi gibi öğretmenin bilgi hem de deneyim ile kendini geliştirebileceği bir alanda öğretmenlerin birbirleriyle bilgi ve tecrübelerini paylaşarak etkileşime geçebilecekleri ortamlar tasarlanmalıdır.

Yaratıcı drama, yöntem olarak bu araştımada öğretmen adaylarının eğitimi için işe koşulmuştur. Öğretmenlerin ve öğretmen adaylarının meslekteki çalışma süresi ve çalışma koşulları, mesleklerine karşı besledikleri duygu ve tutumlarına paralel olarak mesleki anlamda kendilerini yenilemeleri, eğitim dünyasındaki yeni gelişmeleri takip ederek bunları sınıf ortamında yaşatma istekleri beklenen düzeyde değildir. Öğretmen adaylarının mesleki alanlarında sınıf yönetimi gibi uygulamaya dayalı derslerde beklenen düzeyde bilgi ve beceri geliştirebilmeleri için yine uygulamaya dayalı bir alan olan yaratıcı drama yer almalıdır.

\section{Kaynaklar}

Adıgüzel, H. Ö. (2006) Yaratıcı Drama Dergisi "Yaratıcı drama kavramı, bileşenleri ve aşamaları. 1, 17-27.

Celep, S. (2008). Sınıf yönetiminde kuram ve uygulama (3. baskı). Ankara: PegamA Yayınları.

Güneş, F. (2007). Yapılandırmacı yaklaşımla sınıf yönetimi (1. baskı) Ankara: Nobel Yayın Dağıtım.

Turan, S. ve Şişman, M. (Ed.). (2007). Sınıf Yönetimi (5.baskı).Ankara: Öğreti Yayınları.

Üstündağ, T. (2003). Yaratıcı drama öğretmenimin günlüğ̈̈. Pegema yayıncılık: Ankara.

Yıldırım, A., ve Şimşek, H. (2003). Sosyal bilimlerde araştırma yöntemleri. Ankara: Seçkin yayınları. 


\title{
The Use of Basic Methods on Classroom Management Through Creative Drama
}

\author{
Şeyda Orhan ${ }^{3}$
}

\section{Özlem Öznur Gökbulut ${ }^{4}$}

\section{Introduction}

The classroom is where the process of teaching and educational activities takes place and the students spend most of their time there during this process. That's the reason why all the elements and components of the classroom management need to be organized well. Each class has a unique atmosphere. Consequently, it's the teacher who needs to manage the classroom by taking all the things which form this unique atmosphere into consideration.

Having started to teaching officially, the teachers tend to be strict authoritarian in terms of classroom management despite the fact that they tend to have humanistic attitudes towards the students while managing the classroom as prospective teachers. This may sing the case that current education of classroom management fails to be relevant to the conditions of the real classroom atmosphere (Celep, 2007).

The purpose of the paper is to present some valuable information to prospective teachers of various fields regarding classroom management The main title of the project, classroom management, is classified in subtitles as follows; some basic elements of classroom management, factors influencing classroom management, qualifications about classroom management that teachers should possess, undesired behaviors in class.

\section{Methods}

Quantitative and qualitative methods are both used in the project. 'Classroom Management Skills Observation Scale' by Delson (1982) was used as preliminary and conclusion test, which is verified by Yalcinkaya and Tonbul (2002) Quantitative datum of the workshop were collected through open ended questions directed to prospective teachers before and after the application of the project.

Methods and techniques used in the workshop are creative drama technique and inanimate image regarding the method, role corridor, method of teaching via techniques on involvement of the leader, answerquestion and concept map.

The project was carried out through the use of creative drama technique aiming to employ the elements of classroom management by 27 volunteer students of EYAT (Ankara University Creative Drama Education Society) during six sessions of three hours totaling 18 hours.

\section{Result and Suggestions}

As a result, creative drama methods influenced prospective teachers in a positive way helping them coping with classroom management and undesired behaviors. Thus, the use of creative drama which is also an applied course as classroom management in educating prospective teachers. Through the use of different methods like creative drama, teachers and prospective teachers should be encouraged to apply new developments in education area in parallel to the working conditions in the profession, time period and their approach and feelings towards their profession.

3 Teacher, Ministry Education, seydaooorhan@gmail.com

4 Teacher, Ministry Education, ooozlemgokbulut@gmail.com 